\title{
Where to Start? A Two Stage Residual Inclusion Approach to Estimating Influence of the Initial Provider on Health Care Utilization and Costs for Low Back Pain in the US
}

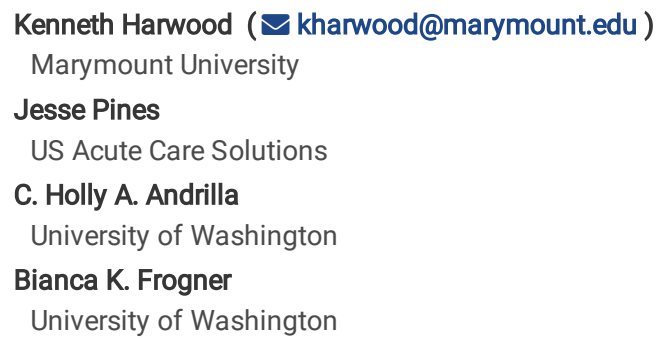

Research Article

Keywords: low back pain, health care utilization, opioids, health care costs, insurance claims, conservative care

Posted Date: July 9th, 2021

DOI: https://doi.org/10.21203/rs.3.rs-668823/v1

License: (c) (1) This work is licensed under a Creative Commons Attribution 4.0 International License. Read Full License 


\section{Abstract}

Background: Diagnostic testing and treatment recommendations can vary when medical care is sought by individuals for low back pain (LBP), leading to variation in quality and costs of care. We examine how first provider seen by an individual at initial diagnosis of LBP influences downstream utilization and costs.

Methods: Using national private health insurance claims data, individuals age 18 or older were retrospectively assigned to cohorts based on the first provider seen at the index date of LBP diagnosis. Exclusion criteria included individuals with a diagnosis of LBP or any serious medical conditions, or an opioid prescription recorded in the six months prior to the index date. Outcome measures included use of imaging, back surgery rates, hospitalization rates, emergency department visits, early- and long-term opioid use, and costs (out-of-pocket and total costs of care) twelve months post-index date. We used a common econometric technique, two-stage residual inclusion (2SRI) estimation to reduce selection bias in the choice of first provider, controlling for demographics.

Results: Among 3,799,593 individuals, cost and utilization varied considerably based on first provider seen by the patient. The frequency of early opioid prescription was significantly lower when care began with an acupuncturist or chiropractor, and highest for those who began with an emergency medicine physician or advanced practice registered nurse (APRN). Long-term opioid prescriptions were low across most providers except physical medicine and rehabilitation physicians and APRNs. The frequency and time to serious illness varied little across providers. Total cost of care was lowest when starting with a chiropractor $(\$ 5,093)$ or primary care physician $(\$ 5,660)$, and highest when starting with an orthopedist $(\$ 9,434)$ or acupuncturist $(\$ 9,205)$.

Conclusion: The first provider seen by individuals with LBP was associated with large differences in health care utilization, opioid prescriptions, and cost while there were no differences in delays in diagnosis of serious illness.

\section{Background}

Low back pain (LBP) is a common, often self-limiting yet costly condition that significantly impacts the lives of individuals. Up to 80 of the US population will have LBP at least once in a lifetime.(1) Nearly a quarter of individuals with LBP report physical function limitations.(2) Total annual costs for LBP was estimated at $\$ 100$ to 200 billion in the US(3) with LBP health care costs growing at a pace greater than non-LBP expenditures.(2)

LBP is a common reason for individuals to seek health care services in the US.(4) For example, one study found that one in every 17 visits to a general medicine provider was for LBP.(5) For physical therapists and chiropractors, LBP is the most common diagnosis for individuals seeking care.(6)(7) Currently, there is growing interest in the effects of health care utilization and costs and the provider type that initiates care. For a majority of the US population, a physician typically initiates heath care services.(8) However, other providers are increasingly acting as entry points into the health care system.(9) (10)

A growing body of literature has found significant variation in LBP health care utilization and costs associated with the providers initiating care, suggesting that provider role and ordering in the care pathway may be important factors when considering methods to reduce costs. Our group(11) examined 2009-2013 private health insurance claims data from the Health Care Cost Institute $(\mathrm{HCCl})$ in six Pacific Northwest states. We found that adult, non-elderly individuals with LBP who were seen by a physical therapist (PT) first had an 89 lower probability of receiving an opioid prescription, 28 lower probability of having any advanced imaging services and 15 lower probability of emergency department (ED) visits. There were also lower outpatient, pharmacy and out-of-pocket costs. Liu and colleagues(12) used 2008-2014 private health insurance claims data from MarketScan to compare cost and utilization differences for individuals with LBP who never saw a PT or saw a PT immediately ( $\leq 3$ days from index date), early (4-14 days), delayed (15-28 days), or late (29-90 days). Among individuals who saw a PT, the authors found seeing a PT immediately had the lowest opioid medication use, ED use, pain medication, advanced imaging and non-LBP-related costs. Kazis and colleagues(13) used 2008-2013 private health insurance claims data from Optum to investigate the effects of initial provider seen on short- and long-term opioid use for individuals with LBP. The researchers found that individuals who saw a PT or chiropractor had lower odds of receiving short- and long-term opioids as compared to a primary care provider. In addition, physician specialty may affect the downstream costs and utilization. Fox et al.(14) found that mandatory physiatry consultation prior to LBP surgery decreased surgical rates by 25 and decreased overall cost of care.

The aims of the study were to determine the extent to which the first provider seen for LBP impacts health care costs and utilization, including short- and longterm opioid use, imaging, hospitalizations, out-of-pocket costs, and total costs, using a large national health insurance claims database. Where other studies used propensity score matching to control for selection bias,(12)(13) we applied a common econometric technique for causal inference called a two-stage residual inclusion (2SRI) estimation approach, which is an instrumental variables approach best suited for non-linear models while controlling for selection bias inherent in observational studies.(15) While randomized control trials are the gold standard for comparing interventions, this study provides a large-scale, real-world look at the complexity of and variation in LBP care that may be influenced by the first healthcare provider seen.

\section{Methods}

\section{Sample and study design}

We reviewed all eligible insurance claims for LBP using the 2015-2016 Health Care Cost Institute (HCCl) database that includes health insurance claims data for approximately 50 million insured individuals per year in the US, across four private health insurance companies (Aetna, Humana, United Healthcare, and Kaiser Permanente) including claims covered by a Medicare Advantage plan. The data that support the findings of this study are available from Health Care 
Cost Institute ( $\mathrm{HCCl}$, https://healthcostinstitute.org) but restrictions apply to the availability of these data, which were used under license for the current study, and so are not publicly available. $\mathrm{HCCl}$ is an independent, non-profit organization that licenses access to insurance claims data for a fee via secure enclave.

Data are however available from the authors upon reasonable request and with permission of HCCl that may require an additional fee. We merged county-level data from the 2015 Area Health Resource File (AHRF) and distance information from the National Bureau of Economic Research (NBER).(16) (17)

We restricted the sample to include individuals 18 years or older who lived and received services within the 50 states and the District of Columbia. We further restricted the sample to those individuals who had continuous enrollment for one-year after an initial primary diagnosis of LBP, or "index date" of diagnosis.

LBP was defined using ICD9/10-CM codes from the literature that were frequently used to designate LBP diagnoses that should not receive initial radiography or opioids, and respond best to conservative care (S1 Table A).(18)(19) Individuals were excluded if they had a diagnosis of LBP, serious illness associated with non-musculoskeletal based LBP (S1 Table B), or an opioid prescription as defined by National Drug Codes identified by the Centers for Disease Control and Prevention(20) six months prior to the index date which we refer to as a "clean period".

We defined cohorts based on the first provider seen on the index date. Provider categories were included in the study based on the most frequent health care providers seen first for an episode of musculoskeletal low back pain in the database. The provider categories examined were: 1) acupuncturist (Acu), 2) advanced practice registered nurse (APRN), 3) chiropractor (Chiro), 4) emergency medicine (EM), 5) orthopedic specialist (Ortho), 6) physical medicine and rehabilitation (PM\&R), 7) physical therapist (PT), and 8) primary care physician (PCP) including family medicine, internal medicine, and osteopathic medicine. All other provider types not specified above were collapsed into a category of "Other". The six most common other provider types that made up about 75 of this category included radiology (23), anesthesiology (17), unknown provider type (15), other non-physician provider (6), and neurological surgeon (5). We assumed that these providers were not common choices for an individual with a new diagnosis of LBP, but we kept this other category in the analysis to maximize sample size. For PT, we used the Current Procedural Terminology (CPT) code 97001, which is an evaluation code for new PT visits and excluded individuals with the follow-up examination CPT code (97002).

In some cases, individuals saw more than one provider on the index date. We excluded these individuals to ensure a uniform analysis of treatment decisions associated with the first provider. Of the 525,663 excluded, approximately 25 saw a PCP, 20 saw an EM, and 40 saw an "Other" type of provider; as such, the activities of these groups may be slightly underrepresented. Our final sample size was 3,799,593. The study was fully approved by the George Washington University Institutional Review Board (IRB \# 011814) via expedited review procedures.

\section{Measures}

As our dependent variables, we included several utilization and cost measures within the one-year post-index date. We included a set of binary measures related to opioid prescriptions. To allow for comparison across studies, we used the definition by Kazis and colleagues for early- and long-term opioid prescriptions.(13) Receiving an early opioid prescription was defined as a filled prescription within 30 days or less of the index date. Receiving a long-term opioid prescription was defined as a filled prescription within 60 days or less and either 1) received 120 days or more of pills supplied in the one-year postindex date or 2) received 90 or more days of pills supplied and had 10 or more refills in that one year. We created binary measures for a) diagnostic imaging services, which was defined as whether an individual had magnetic resonance imaging (MRI) or a computed tomography (CT) scan, b) radiography, $\mathrm{C}$ ) surgery related to LBP (Table A in S1 for list of CPT codes), d) ED visit, and e) inpatient hospitalization. A binary measure was created for any serious illness related to LBP (see Table B in S1for ICD-9 or -10 codes) to address concerns about any delays in diagnoses associated with provider types.

We used two measures of costs. First, we defined total health care costs as the net paid amount to the provider after all deductions and calculations over the course of the one-year post-index date. Second, we defined total out-of-pocket costs, which are a subset of total health care costs, to include deductibles, coinsurance, and copays for all visits over the course of the year. Negative or missing values were coded as zero.

Control variables included whether an individual identified at the index date as female or male, age categories (with age 18 to 34 as the reference category and age 75 and older collapsed into one category), whether an individual was in a Medicare Advantage plan, plan type categorized by flexibility of provider referrals (preferred provider organization and exclusive provider organization as the combined reference category; health maintenance organization; point of service; and "other" including private fee-for-service, independent, life insurance, and unknown), whether the individual was in a high deductible plan or not, and an Elixhauser Index value based on all other diagnoses identified on the index date (and accounting for changes in coding from ICD-9 to ICD-10 CM).(21)

Using data from the AHRF, we categorized the county in which an individual lived based by Urban Influence Code (UIC), which accounts for population density and urban influence, collapsed into three categories: metropolitan (reference), micropolitan and noncore (rural).(16)(22) To account for socioeconomic factors influencing the utilization of health care by individuals, we included county typology codes defined by the Economic Research Service (ERS) including whether the county population had low levels of educational attainment (defined as twenty percent or more of the working-age population lacking a high school diploma or equivalent) or low employment levels (defined as less than 65 percent of working age population employed). We tested whether the population had persistent poverty levels. We also included the percent of the county that was uninsured.

\section{Instrumental Variables Estimation}

Observational studies require statistical techniques to control for confounding or selection bias, into an intervention. To control for the selection bias associated with an individual's choice of the first provider seen, which is the variable of interest in our study, we used an econometric technique called instrumental variables (IV) estimation that is commonly used for causal inference in health services research and epidemiological studies.(23)(24) We specifically used the two-stage residual inclusion (2SRI) estimation approach of the IV estimation, which is recommended for use in non-linear modeling to create consistent estimators.(25) An IV estimation requires a variable (the "instrument") that strongly predicts the intervention that an individual receives (i.e., the first provider seen at the index date), but is not directly associated with the outcome measures. We identified the copay associated with the index date as our "instrument", which is a common instrument in the Pharmacoeconomics literature, but infrequently used in health services research. Copay was chosen 
because insurance benefits are designed to direct individuals to see providers with lower copays (typically primary care providers) than providers with higher copays (i.e., specialists). While we expect that copay is likely to influence the initial choice of provider, copays are not expected to affect providers' choice of treatment and thus, our outcomes. For a sensitivity analysis, we also tested differential distance, an instrument used in our previous study,(11)defined as: 1) the distance between an individual and the first provider of choice, and 2) the distance between an individual and the closest alternative provider.

Both instruments were well-over the F-test threshold of 10, a common benchmark for a strong instrument. Given that the sample size was large for this study, achieving this threshold was not surprising. We found the parameter estimates were nearly identical with either instrument, although the standard errors were slightly narrower at the fifth or sixth decimal place using copay over differential distance. Choosing copay preserves more of the sample over differential distance given limitations in defining this instrument. The tradeoff was the loss of information from the nearly three-quarter of a million observations missing distance information.

\section{Statistical Analysis}

We report descriptive statistics for bivariate analyses. In the first stage of the 2SRI, we predict the first provider type seen (PT as reference group) as a function of copay (instrument) and control variables described in the previous section using a multinominal logistic regression model, which is used to estimate categorical variables with no logical ordering. In the second stage, we used probit models to predict the probability for each of our health care utilization measures (e.g., opioid prescription, imaging service, ED visit, hospitalization, surgery, and serious illness) and generalized linear models assuming gamma distribution and using a log link to estimate total and out-of-pocket costs as a function of first provider seen, control variables from the first stage, and the raw residuals from the first stage. We conducted two additional sensitivity analyses: 1) using deviance residuals in place of raw residuals, which produced nearly identical results, and 2) adding state dummies produced similar consistent parameter estimates but we did not include them in the final model at risk of overfitting. We report predicted probabilities for each of the binary outcome measures and the predicted costs for individuals seen by each of the provider types.

\section{Results}

\section{Sociodemographic Statistics}

In our sample of 3,799,593 individuals, 25.2 saw PCP first, followed by Chiro (24.8), Ortho (5.1), PM\&R (4.2), PT (2.9), EM (2.4), APRN (1.6), Acu (1.0) and 32.8 saw a mix of "other" providers (Table 1). The total sample included a greater percentage of females (56.0) versus males (44.0), older individuals in the 55 to 64 age group (21.5), individuals living in a metropolitan area (86.0) versus non-metropolitan area, and individuals in point of service health insurance plans (54.8) versus other plan types. 
Table 1

Sociodemographic Characteristics by First Provider Seen for Low Back Pain

\begin{tabular}{|c|c|c|c|c|c|c|c|c|c|c|c|c|c|c|c|c|c|}
\hline \multirow{3}{*}{ Sample Size } & \multirow{2}{*}{\multicolumn{2}{|c|}{$\begin{array}{l}\text { Total } \\
3,799,593\end{array}$}} & \multirow{2}{*}{$\begin{array}{l}\text { PT } \\
109,480\end{array}$} & \multicolumn{2}{|c|}{ Chiro } & \multicolumn{2}{|c|}{ ACU } & \multicolumn{2}{|c|}{ APRN } & \multicolumn{2}{|c|}{ PCP } & \multicolumn{2}{|c|}{ PM\&R } & \multicolumn{2}{|c|}{ Ortho } & \multicolumn{2}{|c|}{ EM } \\
\hline & & & & & 2,925 & & 522 & & 734 & & 7,619 & & 0,537 & & 2,144 & & 979 \\
\hline & $\begin{array}{l}\text { Mean } \\
(\%)\end{array}$ & $\begin{array}{l}\text { SD } \\
(\%)\end{array}$ & $\begin{array}{l}\text { Mean } \\
(\%)\end{array}$ & $\begin{array}{l}\text { SD } \\
(\%)\end{array}$ & $\begin{array}{l}\text { Mean } \\
(\%)\end{array}$ & $\begin{array}{l}\text { SD } \\
(\%)\end{array}$ & $\begin{array}{l}\text { Mean } \\
(\%)\end{array}$ & $\begin{array}{l}\text { SD } \\
(\%)\end{array}$ & $\begin{array}{l}\text { Mean } \\
(\%)\end{array}$ & $\begin{array}{l}\text { SD } \\
(\%)\end{array}$ & $\begin{array}{l}\text { Mean } \\
(\%)\end{array}$ & $\begin{array}{l}\text { SD } \\
(\%)\end{array}$ & $\begin{array}{l}\text { Mean } \\
(\%)\end{array}$ & $\begin{array}{l}\text { SD } \\
(\%)\end{array}$ & $\begin{array}{l}\text { Mean } \\
(\%)\end{array}$ & $\begin{array}{l}\text { SD } \\
(\%)\end{array}$ & $\begin{array}{l}\text { Mea } \\
(\%)\end{array}$ \\
\hline Female & 56.0 & 49.6 & 60.4 & 48.9 & 53.4 & 49.9 & 63.3 & 48.2 & 58.5 & 49.3 & 54.3 & 49.8 & 58.4 & 49.3 & 56.1 & 49.6 & 53.9 \\
\hline Age 18-34 & 16.4 & 37.1 & 18.4 & 38.7 & 22.9 & 42.0 & 23.0 & 42.1 & 18.6 & 38.9 & 14.7 & 35.4 & 9.8 & 29.8 & 11.9 & 32.4 & 27.4 \\
\hline Age $35-44$ & 16.4 & 37.1 & 17.3 & 37.8 & 20.2 & 40.2 & 30.2 & 45.9 & 18.4 & 38.7 & 16.4 & 37.0 & 13.3 & 33.9 & 12.8 & 33.4 & 21.7 \\
\hline Age 45-54 & 20.5 & 40.3 & 19.9 & 39.9 & 21.1 & 40.8 & 25.3 & 43.5 & 22.3 & 41.7 & 21.2 & 40.9 & 20.3 & 40.2 & 19.3 & 39.5 & 20.7 \\
\hline Age 55-64 & 21.5 & 41.1 & 20.7 & 40.5 & 18.2 & 38.6 & 15.5 & 36.2 & 21.8 & 41.3 & 22.8 & 42.0 & 24.8 & 43.2 & 23.8 & 42.6 & 15.8 \\
\hline Age $65-74$ & 14.9 & 35.6 & 14.2 & 34.9 & 11.3 & 31.7 & 4.6 & 20.9 & 10.9 & 31.1 & 14.9 & 35.6 & 19.2 & 39.4 & 19.1 & 39.3 & 8.6 \\
\hline Age 75+ & 10.2 & 30.3 & 9.5 & 29.3 & 6.2 & 24.1 & 1.4 & 12.0 & 8.0 & 27.2 & 10.0 & 30.0 & 12.6 & 33.2 & 13.0 & 33.6 & 5.9 \\
\hline $\begin{array}{l}\text { Elixhauser } \\
\text { Index (\#) }\end{array}$ & 0.04 & 0.22 & 0.02 & 0.14 & 0.02 & 0.14 & 0.01 & 0.10 & 0.04 & 0.21 & 0.05 & 0.23 & 0.04 & 0.21 & 0.03 & 0.16 & 0.03 \\
\hline $\begin{array}{l}\text { Medicare } \\
\text { Advantage }\end{array}$ & 23.0 & 42.1 & 15.6 & 36.3 & 12.7 & 33.3 & 1.9 & 13.6 & 16.9 & 37.5 & 24.4 & 42.9 & 33.3 & 47.1 & 27.4 & 44.6 & 14.7 \\
\hline PPO/EPO & 27.9 & 44.9 & 26.4 & 44.1 & 23.7 & 42.5 & 16.4 & 37.0 & 21.0 & 40.7 & 27.5 & 44.7 & 31.0 & 46.3 & 29.7 & 45.7 & 21.8 \\
\hline POS & 54.8 & 49.8 & 60.8 & 48.8 & 67.6 & 46.8 & 80.7 & 39.5 & 64.5 & 47.9 & 52.8 & 49.9 & 46.2 & 49.9 & 51.0 & 50.0 & 58.9 \\
\hline HMO & 14.0 & 34.7 & 9.0 & 28.6 & 6.1 & 24.0 & 2.4 & 15.4 & 11.1 & 31.4 & 16.8 & 37.3 & 19.6 & 39.7 & 15.5 & 36.2 & 17.6 \\
\hline Other & 3.2 & 17.7 & 3.8 & 19.1 & 2.6 & 15.8 & 0.6 & 7.5 & 3.5 & 18.3 & 2.9 & 16.9 & 3.2 & 17.6 & 3.8 & 19.0 & 1.6 \\
\hline $\begin{array}{l}\text { Not in High } \\
\text { Deduct Plan }\end{array}$ & 72.4 & 44.7 & 69.6 & 46.0 & 67.2 & 47.0 & 70.2 & 45.7 & 68.3 & 46.5 & 73.7 & 44.0 & 75.6 & 43.0 & 73.1 & 44.3 & 71.9 \\
\hline $\begin{array}{l}\text { High } \\
\text { Deductible } \\
\text { Plan }\end{array}$ & 22.3 & 41.6 & 24.1 & 42.7 & 28.6 & 45.2 & 28.3 & 45.0 & 24.3 & 42.9 & 21.2 & 40.9 & 18.9 & 39.1 & 21.2 & 40.8 & 25.5 \\
\hline $\begin{array}{l}\text { Unknown } \\
\text { High } \\
\text { Deductible }\end{array}$ & 5.3 & 22.3 & 6.4 & 24.4 & 4.2 & 20.1 & 1.5 & 12.1 & 7.3 & 26.1 & 5.1 & 21.9 & 5.5 & 22.9 & 5.7 & 23.2 & 2.5 \\
\hline $\begin{array}{l}\text { Metropolitan } \\
\text { (UIC) }\end{array}$ & 86.0 & 34.7 & 91.8 & 27.5 & 84.7 & 36.0 & 98.0 & 14.1 & 77.5 & 41.8 & 85.4 & 35.3 & 90.3 & 29.6 & 89.7 & 30.3 & 90.7 \\
\hline $\begin{array}{l}\text { Micropolitan } \\
\text { (UIC) }\end{array}$ & 6.5 & 24.7 & 3.8 & 19.1 & 7.7 & 26.6 & 0.7 & 8.2 & 11.1 & 31.4 & 6.6 & 24.9 & 4.7 & 21.2 & 4.8 & 21.4 & 4.4 \\
\hline $\begin{array}{l}\text { Noncore } \\
\text { (UIC) }\end{array}$ & 7.5 & 26.4 & 4.4 & 20.6 & 7.6 & 26.5 & 1.3 & 11.5 & 11.5 & 31.9 & 8.0 & 27.1 & 5.0 & 21.8 & 5.4 & 22.7 & 5.0 \\
\hline $\begin{array}{l}\text { County: Low } \\
\text { Education }\end{array}$ & 8.4 & 27.8 & 5.7 & 23.1 & 7.3 & 26.0 & 10.2 & 30.3 & 8.8 & 28.3 & 9.8 & 29.8 & 5.6 & 23.0 & 9.4 & 29.2 & 8.6 \\
\hline $\begin{array}{l}\text { County: Low } \\
\text { Employ }\end{array}$ & 11.0 & 31.3 & 6.6 & 24.9 & 8.9 & 28.5 & 2.0 & 14.1 & 15.7 & 36.4 & 12.7 & 33.3 & 9.1 & 28.8 & 9.6 & 29.5 & 9.0 \\
\hline $\begin{array}{l}\text { County: } \\
\text { High Poverty }\end{array}$ & 11.8 & 32.3 & 9.5 & 29.3 & 9.4 & 29.2 & 4.5 & 20.8 & 16.2 & 36.8 & 13.5 & 34.2 & 10.3 & 30.4 & 11.0 & 31.3 & 10.6 \\
\hline $\begin{array}{l}\text { County } \\
\text { Uninsured }\end{array}$ & 11.0 & 5.0 & 9.5 & 4.4 & 10.3 & 4.9 & 8.6 & 4.1 & 10.8 & 4.9 & 11.4 & 5.0 & 10.8 & 4.6 & 11.6 & 5.0 & 11.2 \\
\hline
\end{tabular}

\section{Health Care Utilization and Costs}

Results from the 2SRI demonstrated considerable variation in health care utilization after accounting for selection for the first provider seen by individuals with LBP (Fig. 1). Table 2 includes the marginal rates with the corresponding standard error. 
Table 2

Health Care Utilization and Serious Illnesses by First Provider Seen for Low Back Pain

\begin{tabular}{|c|c|c|c|c|c|c|c|c|c|c|c|c|c|c|c|}
\hline & \multicolumn{2}{|c|}{ Early Opioid Rx } & \multicolumn{2}{|c|}{ Long Opioid Rx } & \multicolumn{2}{|c|}{ Had MRI/CT } & \multicolumn{2}{|c|}{$\begin{array}{l}\text { Had } \\
\text { Radiography }\end{array}$} & \multicolumn{2}{|c|}{ Had ED Visit } & \multicolumn{2}{|c|}{$\begin{array}{l}\text { Had } \\
\text { Hospitalization }\end{array}$} & \multicolumn{2}{|c|}{ Had Surgery } & \multirow{2}{*}{$\begin{array}{l}\text { Had Seric } \\
\text { Illness }\end{array}$} \\
\hline & Margin & SE & Margin & SE & Margin & SE & Margin & SE & Margin & SE & Margin & SE & Margin & SE & \\
\hline PT & 3.2 & 0.058 & 1.4 & 0.040 & 16.1 & 0.112 & 11.0 & 0.096 & 16.5 & 0.114 & 7.4 & 0.081 & 2.3 & 0.046 & 22.9 \\
\hline Chiro & 1.7 & 0.015 & 0.6 & 0.009 & 6.7 & 0.027 & 17.4 & 0.040 & 43.3 & 0.053 & 5.8 & 0.026 & 0.7 & 0.009 & 19.2 \\
\hline ACU & 1.2 & 0.069 & 0.4 & 0.045 & 5.7 & 0.127 & 5.9 & 0.125 & 18.7 & 0.209 & 8.4 & 0.166 & 0.5 & 0.039 & 22.1 \\
\hline APRN & 11.2 & 0.127 & 5.3 & 0.090 & 18.2 & 0.157 & 19.7 & 0.162 & 19.1 & 0.158 & 8.0 & 0.112 & 2.7 & 0.066 & 21.8 \\
\hline PCP & 9.9 & 0.030 & 3.6 & 0.018 & 16.4 & 0.038 & 17.6 & 0.039 & 17.0 & 0.038 & 6.5 & 0.025 & 1.9 & 0.014 & 19.9 \\
\hline PM\&R & 11.1 & 0.073 & 6.3 & 0.055 & 27.4 & 0.111 & 20.5 & 0.101 & 19.3 & 0.096 & 8.7 & 0.067 & 3.7 & 0.047 & 24.6 \\
\hline Ortho & 8.0 & 0.060 & 2.5 & 0.034 & 36.8 & 0.110 & 47.4 & 0.115 & 17.6 & 0.086 & 10.0 & 0.066 & 6.8 & 0.057 & 25.9 \\
\hline EM & 12.6 & 0.109 & 1.9 & 0.048 & 16.7 & 0.126 & 20.6 & 0.134 & 34.5 & 0.154 & 8.6 & 0.096 & 2.0 & 0.048 & 21.7 \\
\hline Other & 10.1 & 0.026 & 4.8 & 0.018 & 30.4 & 0.041 & 25.8 & 0.039 & 24.8 & 0.038 & 10.4 & 0.026 & 4.2 & 0.018 & 24.8 \\
\hline
\end{tabular}

PT = physical therapist; Chiro = chiropractor; $\mathrm{ACU}=$ Acupuncturist; $\mathrm{APRN}=$ advanced practice registered nurse; $\mathrm{PCP}=$ primary care physicians; $\mathrm{PM} \& \mathrm{R}=$ physical medicine and rehabilitation physician ; Ortho = orthopedist; EM = emergency medicine physician

Radiography and MRI/CT: The use of radiography and MRI/CT varied widely depending upon the first provider seen (Fig. 1, Table 2). Individuals that first saw Ortho (47.4, SE: 0.1) had highest use of radiography; Acu (5.9, SE: 0.1) and PT (11.0, SE: 0.1) had the lowest rates of radiography use. Individuals who first saw Ortho (36.8, SE: 0.1), had highest utilization of MRI/CT; whereas individuals that first saw Acu (5.7, SE: 0.1) and Chiro (6.7, SE: 0.0) were less likely to have MRI/CT.

Hospitalization, ED Visits, Back Surgery, Serious IIIness: Hospitalization rates had relatively small variation among the providers with the overall rate being relatively low (7.4, SE: 0.0) (Fig. 1, Table 2). Individuals that first saw Ortho (10.0, SE: 0.0) were most likely to have had a hospitalization whereas individuals that first saw Chiro $(5.8, \mathrm{SE}: 0.0)$ and PCP $(6.5, \mathrm{SE}: 0.0)$ were least likely to be hospitalized. Individual that first saw Ortho were more likely to have back surgery $(6.8$, SE: $0.1 ; 4.2$, SE: 0.0 , respectively) whereas individuals that saw Acu $(0.5, \mathrm{SE}: 0.0)$ and Chiro $(0.7, \mathrm{SE}: 0.0)$ were least likely to have had back surgery. ED visits during the follow-up period showed wide variation in frequency as individuals who saw a Chiro first had the highest probability of an ED visit (43.3, SE: 0.1) followed by EM (34.5, SE: 0.2), whereas the least likely was PT (16.5, SE: 0.1) and PCP (17.0, SE: 0.0).

The frequency of serious illness diagnoses that are associated with LBP symptoms (red flags and common non-musculoskeletal diagnoses that refer to LBP - Table B in S1) during the one-year follow-up was 22 (SD: 42). The frequency did not vary significantly across providers (19-25). The time to serious illness diagnosis (number of days from index date to diagnosis date) was 125 days (SD 98 days). Similarly, the time to serious illness diagnosis was not significantly different among providers (104 - 144 days with SE: 95-98 days).

Opioids: The frequency of early opioid prescription was significantly lower for individuals who first saw Acu (1.2, SE: 0.1) and Chiro (1.7, SE: 0.0). Individuals that saw EM (12.6, SE: 0.1) and APRN (11.2, SE: 0.1) had relatively higher frequency of early opioid prescription (Fig. 2). Overall, long-term opioid prescriptions were lower for all providers compared to early opioid prescriptions. Individuals that first saw PMR $(6.3$, SE: 0.1$)$ and APRN $(5.3$, SE: 0.1$)$ had the highest rates of receiving a long-term opioid prescription, while individuals being seen first by Acu $(0.4$, SE: 0.0$)$ and Chiro $(0.6$, SE 0.0$)$ were least likely to receive a long opioid prescription.

Rank Order of Providers for Each Healthcare Outcome Variable: In order to summarize the results of the health care utilization of the first providers seen by individuals with LBP, we rank-ordered the highest to lowest users for each health care utilization variable though noting that the difference between margin rates was minimal in some cases (Table 3). Generally, individuals who first started with a Chiro, Acu or PT ranked lowest in health care utilization across all measures of interest. 
Table 3

Healthcare Category Ranking by First Provider Seen (Highest Use $=1$, Lowest Use $=9$ )

\begin{tabular}{|llllllllll|}
\hline & PT & Chiro & Acu & APRN & PCP & PM\&R & Ortho & EM & Other \\
\hline Early Opioid Rx & 7 & 8 & 9 & 2 & 5 & 3 & 6 & 1 & 4 \\
\hline Long Opioid Rx & 7 & 8 & 9 & 2 & 4 & 1 & 5 & 6 & 3 \\
\hline MRI/CT & 7 & 8 & 9 & 4 & 6 & 3 & 1 & 5 & 2 \\
\hline Any Radiography & 8 & 7 & 9 & 5 & 6 & 4 & 1 & 3 & 2 \\
\hline Had ED Visit & 9 & 1 & 6 & 5 & 8 & 4 & 7 & 2 & 3 \\
\hline Hospitalization & 7 & 9 & 5 & 6 & 8 & 3 & 2 & 5 & 1 \\
\hline Had Surgery & 5 & 8 & 9 & 4 & 7 & 3 & 1 & 6 & 2 \\
\hline Had Serious Illness & 4 & 9 & 5 & 6 & 8 & 3 & 1 & 7 & 2 \\
\hline
\end{tabular}

Health Care Costs: Total cost of care was lowest for individuals (Fig. 3) who first saw Chiro (\$5,093, SE: $\$ 15.99)$ and PCPs (\$5,660, SE: \$17.84) and highest for individuals who saw Ortho $(\$ 9,434$, SE: $\$ 56.53)$ first. Out-of-pocket costs were the least for individuals that saw a PCP (\$853, SE: \$1.57) and Chiro (\$911, SE: \$1.55) first and highest for those individuals that saw Acu $(\$ 1,415$, SE: $\$ 8.96)$, and PM\&R $(\$ 1,238, S E: \$ 4.74)$ first.

\section{Limitations}

The study had several limitations. LBP is a condition that may recur over one's lifespan so determining the exact onset of LBP symptoms was not feasible. We attempted to mitigate pre-existing back pain by defining a clean period, excluding individuals with health conditions that cause LBP symptoms for six months prior to index date, which is consistent with other studies.(10)(13) However, given that the Other category includes radiology, anesthesiology, and neurosurgery suggests that individuals may be midcourse in treatment that started prior to the clean period. Our IV estimation approach allows us to keep this Other group, preserving sample size while keeping our ability to isolate the effect of the initial providers on utilization patterns and costs.

Another limitation of claims data is the inability to examine health outcomes, such as functional recovery and return to work. As a proxy, we examined frequency and timing to serious illness that may be related to LBP as a safety outcome. The mean rate and time to serious illness varied little among the different diagnoses and the trends were similar among all providers. Given the time to diagnosis in most cases was approximately 125 days post initial LBP diagnosis, it is difficult to determine whether the index diagnosis was a misdiagnosis that replicated LBP or a new diagnosis that developed over the intervening time. Further research is needed to explore the relationship between serious illness (frequency and time) associated to LBP and initial provider seen.

Despite using a robust econometric approach to establish causality between first provider seen and health outcomes, we are limited in identifying all the factors associated with the first provider selection. For example, individuals who saw EM physicians may have had more serious symptoms or pain, or symptoms may have been refractory to other treatments that were not controlled for using our instrumental variables approach. This may have explained why long-term opioid use may have been somewhat higher in this group despite that emergency physicians do not see individuals longitudinally after the first visit. While a prospective randomized control trial remains the gold standard for controlling for selection bias, this study provides a large scale, national view of the complex and real-world relationship between the first provider and subsequent health care utilization and costs.

Claims data do not provide information on insurance benefit designs and coverage. Thus, we did not consider the variability in most payment benefits (except copay) for different health care providers or insurance policies. Although we did include insurance type, we are unable to determine the limitations associated with each insurance policy coverage. Finally, identifying who actually provided the services was difficult to determine with certain providers. For example, the rate of services provided by APRN may not be accurate. One recent study of data in Massachusetts found that approximately 25 of continuing evaluation and management codes for APRN office visits were billed "incident to" a physician between 2015 and 2017.(26)

\section{Discussion}

This national study demonstrates that health care utilization, cost, and opioid use significantly varied based on the first health care provider seen by individuals with LBP. This finding confirms other regional or single insurance provider studies that examined health care utilization, opioid use, and costs provided by PT, Chiro and PM\&R.(12) (13)This study expands on prior studies by providing a national perspective on how the first provider seen influences multiple health care utilization and cost measures using a robust method to address selection bias.

The findings of this study were similar to other studies exploring the rate by provider type that acted as the entry point into the health care system for LBP. In a retrospective review of claims data in a southwestern University-based health care plan, Fritz et al.(10) reported primary care, chiropractic and physiatry providers were the three most common entry points into the health care system for LBP. Using a national sample, we found PCP, Chiro, and Ortho were seen most commonly as the entry point to health care. We assume that among the variables affecting choice of provider for entry point include state regulation, insurance policy, regional supply of providers, and personal beliefs and norms. Further study is required to determine the relative impact of these factors on provider type seeking behaviors. 
The first health care provider seen is the entry point into the health care system and affects assessment and intervention strategies that lead to significant variance in health care utilization and cost. For example, expensive MRIs have been shown to be used more by Ortho and PM\&R whereas individuals that first saw Chiro and Acu had significantly less MRI use over the one-year follow-up. This finding may be partially explained by legal and regulatory restrictions in ordering MRI and radiology based on provider type (e.g., Acu cannot order MRIs in the US). However, the restrictions do not explain the variance among approved prescribers (e.g., various physician types, PRNs). Dietrich et al. (27)found significant differences among US Military Health Services physician assistants, APRNs, and physicians in ordering MRI and radiography, opioids, and anti-inflammatory medications in individuals with LBP. Differences among allowed prescribers may reflect practice habits or professional education differences. Further study is warranted.

The variances seen in early- and long-term opioid prescriptions rates are concerning given the ongoing opioid crisis. The study demonstrated that EM, PM\&R, and APRN had higher early and long-term opioids prescription rates than for Acu, Chiros, or PTs. We may assume since Acu, Chiros, and PTs cannot currently prescribe opioids, they will have lower prescription rates. However, our study investigated the full episode of care with one year follow-up including all subsequent health care utilization. It was likely that individuals initiating care with Acu, Chiros, or PTs saw allowable prescribers before or after the initial visit. Our study suggests that the initial provider may play an important role in setting the course of treatment and providers seen throughout the full episode of care. Evidence suggests that health care provider habits may influence patient treatment. Barnett, et al. (28)report that individuals visiting the ED and treated by high intensity opioid prescribers were more likely to be long-term opioid users. Additionally, the opioid prescription rate, although relatively low for some providers, remains a concern and is incongruent with most clinical practice guidelines.(29)

A surprising finding was the high rate of ED visits for individuals with LBP seeing Chiros first. In a secondary analysis of 2012 National Health Interview Survey data, Forte and Maiers ${ }^{24}$ found one in four individuals 65 years or older who saw chiropractors reported at least one ED visit in the prior 12 months. Interestingly, the ED visit rate between those that reported having manipulation was comparable to controls (no manipulation). Further research may prove helpful in understanding these findings.

Our findings show that POS plans were more often held by individuals who seek more conservative or complimentary providers perhaps suggesting opportunities for modifications to HMO and PPO plan provisions. Notably, the presence of high deductible plans was equally common for individuals across all providers. Given the need to tighten economic spending due to COVID, US policymakers are seeking ways to encourage individuals to get low cost but high value care (i.e., care that follows clinical practice guidelines). While we have limited information on health outcomes, our findings support that some conservative providers deliver lower cost while providing care aligned with clinical practice guidelines. With scope of practice laws being relaxed across states temporarily due to the COVID crisis, the country is going through a natural experiment as individuals have greater access to varied providers. While these practice laws may change, our results suggest that policymakers should consider less restrictive laws so as to not limit access to effective providers.

\section{Conclusions}

The study found that health care utilization and cost was affected by health care provider type seen on the initial visit for individuals with LBP. The first health care provider seen may also affect the use of evidence-based clinical practice guidelines. Finally, early and long-term opioid use for individuals with LBP varied significantly based on the initial health care provider. This study suggests that US policymakers should consider current insurance, regulatory and government policy to encourage patients to seek care from providers that follow clinical practice guidelines. Further research is needed to explore the reasons for cost and utilization differences among the providers.

\section{Declarations}

\section{Ethics approval and consent to participate}

The study was fully approved by the George Washington University Institutional Review Board (IRB\# 011814) via expedited review procedures.

\section{Consent for publication}

Not applicable

\section{Availability of data and materials}

The data that support the findings of this study are available from Health Care Cost Institute (HCCl, https://healthcostinstitute.org) but restrictions apply to the availability of these data, which were used under license for the current study, and so are not publicly available. $\mathrm{HCCl}$ is an independent, non-profit organization that licenses access to insurance claims data for a fee via secure enclave. Data are however available from the authors upon reasonable request and with permission of $\mathrm{HCCl}$ that may require an additional fee.

\section{Competing interests}

$\mathrm{KH}$ : Current funding form Lewin group, under contract with the US Centers for Medicare and Medicaid for unrelated work.

JP: Consultant to CSL Behring, Medtronic, NovoNordisk and Abbott Point-of-Care on unrelated work.

BF \& HA have no competing interests.

Funding 
This research has been supported in part by a Health Services Research Pipeline Grant for the Foundation for Physical Therapy Research

(https://foundation4pt.org/). The funders had no role in study design, data collection and analysis, decision to publish, or preparation of the manuscript.

\section{Authors' contributions}

$\mathrm{KH}, \mathrm{JP}, \mathrm{HA}$ and BF contributed to the study design, implementation, analysis and writing the manuscript. HA and BF performed database management and statistics. KH prepared tables and figures. All authors reviewed the manuscript prior to submission

\section{Acknowledgements}

This research has been supported in part by a Health Services Research Pipeline Grant for the Foundation for Physical Therapy Research through a generous donation by the American Physical Therapy Association. Thank you to the participants of the PHENOM Fall Seminar Series at University of Washington for input on early analyses presented on November 13, 2019.

\section{References}

1. Maher C, Underwood M, Buchbinder R. Non-specific low back pain. Lancet 2017 February 18;389(10070):736-747.

2. Martin BI, Turner JA, Mirza SK, Lee MJ, Comstock BA, Deyo RA. Trends in health care expenditures, utilization, and health status among US adults with spine problems, 1997-2006. Spine (Phila Pa 1976) 2009 September 01;34(19):2077-2084.

3. Ma VY, Chan L, Carruthers KJ. Incidence, prevalence, costs, and impact on disability of common conditions requiring rehabilitation in the United States:Stroke, spinal cord injury, traumatic brain injury, multiple sclerosis, osdetoarthritis, rheumatoid arthritis, limb loss, and back pain. Arch Phys Med Rehabil 2014;95(5):986-995.e1.

4. St Sauver JL, Warner DO, Yawn BP, Jacobson DJ, McGree ME, Pankratz JJ, et al. Why patients visit their doctors: assessing the most prevalent conditions in a defined American population. Mayo Clin Proc 2013 January 01;88(1):56-67.

5. Licciardone JC. The epidemiology and medical management of low back pain during ambulatory medical care visits in the United States. Osteopath Med Prim Care 2008 November 24;2:11-4732.

6. Chevan J, Riddle DL, Reed SD. Out-of-Pocket Spending for Ambulatory Physical Therapy Services From 2008 to 2012: National Panel Survey. Phys Ther 2015 December 01;95(12):1680-1691.

7. Coulter ID, Hurwitz EL, Adams AH, Genovese BJ, Hays R, Shekelle PG. Patients using chiropractors in North America: who are they, and why are they in chiropractic care? Spine (Phila Pa 1976) 2002 February 01;27(3):291-6; discussion 297.

8. Deyo RA, Tsui-Wu YJ. Descriptive epidemiology of low-back pain and its related medical care in the United States. Spine (Phila Pa 1976) 1987 April 01;12(3):264-268.

9. Hart LG, Deyo RA, Cherkin DC. Physician office visits for low back pain. Frequency, clinical evaluation, and treatment patterns from a U.S. national survey. Spine (Phila Pa 1976) 1995 January 01;20(1):11-19.

10. Fritz JM, Kim J, Dorius J. Importance of the type of provider seen to begin health care for a new episode low back pain: associations with future utilization and costs. J Eval Clin Pract 2016 April 01;22(2):247-252.

11. Frogner BK, Harwood K, Andrilla CHA, Schwartz M, Pines JM. Physical Therapy as the First Point of Care to Treat Low Back Pain: An Instrumental Variables Approach to Estimate Impact on Opioid Prescription, Health Care Utilization, and Costs. Health Serv Res 2018 May 23.

12. Liu X, Hanney WJ, Masaracchio M, Kolber MJ, Zhao M, Spaulding AC, et al. Immediate Physical Therapy Initiation in Patients With Acute Low Back Pain Is Associated With a Reduction in Downstream Health Care Utilization and Costs. Phys Ther 2018 May 01;98(5):336-347.

13. Kazis LE, Ameli O, Rothendler J, Garrity B, Cabral H, McDonough C, et al. Observational retrospective study of the association of initial healthcare provider for new-onset low back pain with early and long-term opioid use. BMJ Open 2019 September 20;9(9):e028633-2018.

14. Fox J, Haig AJ, Todey B, Challa S. The effect of required physiatrist consultation on surgery rates for back pain. Spine (Phila Pa 1976) 2013 February 01;38(3):E178-84.

15. Terza JV, Basu A, Rathouz PJ. Two-stage residual inclusion estimation: Addressing endogeneity in health econometric modeling. J Health Econ Invalid date Invalid date;27(3):531-543.

16. Health Resources Service Administration. Area Health Rersources Files. 2019; Available at: https://data.hrsa.gov/topics/health-workforce/ahrf. Accessed $5 / 7,2021$.

17. The National Bureau of Economic Research. Zip code distance database. 2017; Available at: https://data.nber.org/data/zip-code-distance-database.html. Accessed February 4, 2021.

18. Fritz, Julie M P T, Childs, John D P T, Wainner, Robert S P T, Flynn, Timothy W P T. Primary Care Referral of Patients With Low Back Pain to Physical Therapy: Impact on Future Health Care Utilization and Costs. Spine 2012 December 01;37(25):2114-2121.

19. National Committee for Quality Assurance. HEDIS 2013 Technical Specifications for ACO Measurement. Available at: https://www.ncqa.org/search/? $q=$ Technical+Specifications+for+ACO+Measurement+2013. Accessed May 5, 2021.

20. Centers for Disease Control and Prevenbtion. Analyzing prscription data and morphine milligram equivalents (MME). 2019; Available at: https://www.cdc.gov/drugoverdose/resources/data.html. Accessed February 5, 2021.

21. Healthcare Cost and Utilization Project (HCUP). Comorbidity Software, version 3.7. Available at: https://www.hcupus.ahrq.gov/toolssoftware/comorbidity/comorbidity.jsp. Accessed May 7, 2021. 
22. Andrilla CHA, Coulthard C, Patterson DG. Prescribing Practices of Rural Physicians Waivered to Prescribe Buprenorphine. Am J Prev Med 2018 June 01;54(6 Suppl 3):S208-S214.

23. Newhouse JP, McClellan M. Econometrics in outcomes research: the use of instrumental variables. Annu Rev Public Health 1998;19:17-34.

24. Greenland S. An introduction to instrumental variables for epidemiologists. Int J Epidemiol Invalid date Invalid date;29(4):722-729.

25. Terza JV. Two-Stage Residual Inclusion Estimation in Health Services Research and Health Economics. Health Serv Res 2018 June 01;53(3):1890-1899.

26. James H, Auerbach D. HPC Policy Brief: The Nurse Practitioner Workforce and its role in the Massachusetts health care delivery system. 2020; Available at: https://www.mass.gov/doc/policy-brief-the-nurse-practitioner-workforce-and-its-role-in-the-massachusetts-health-care/download. Accessed February, 2021.

27. Dietrich EJ, Leroux T, Santiago CF, Helgeson MD, Richard P, Koehlmoos TP. Assessing practice pattern differences in the treatment of acute low back pain in the United States Military Health System. BMC Health Serv Res 2018 September 17;18(1):720-018.

28. Barnett ML, Olenski AR, Jena AB. Opioid-Prescribing Patterns of Emergency Physicians and Risk of Long-Term Use. N Engl J Med Invalid date Invalid date;376(7):663-673.

29. Chou R, Fanciullo GJ, Fine PG, Adler JA, Ballantyne JC, Davies P, et al. Clinical Guidelines for the Use of Chronic Opioid Therapy in Chronic Noncancer Pain. The Journal of Pain Invalid date Invalid date;10(2):113-130.e22.

\section{Figures}

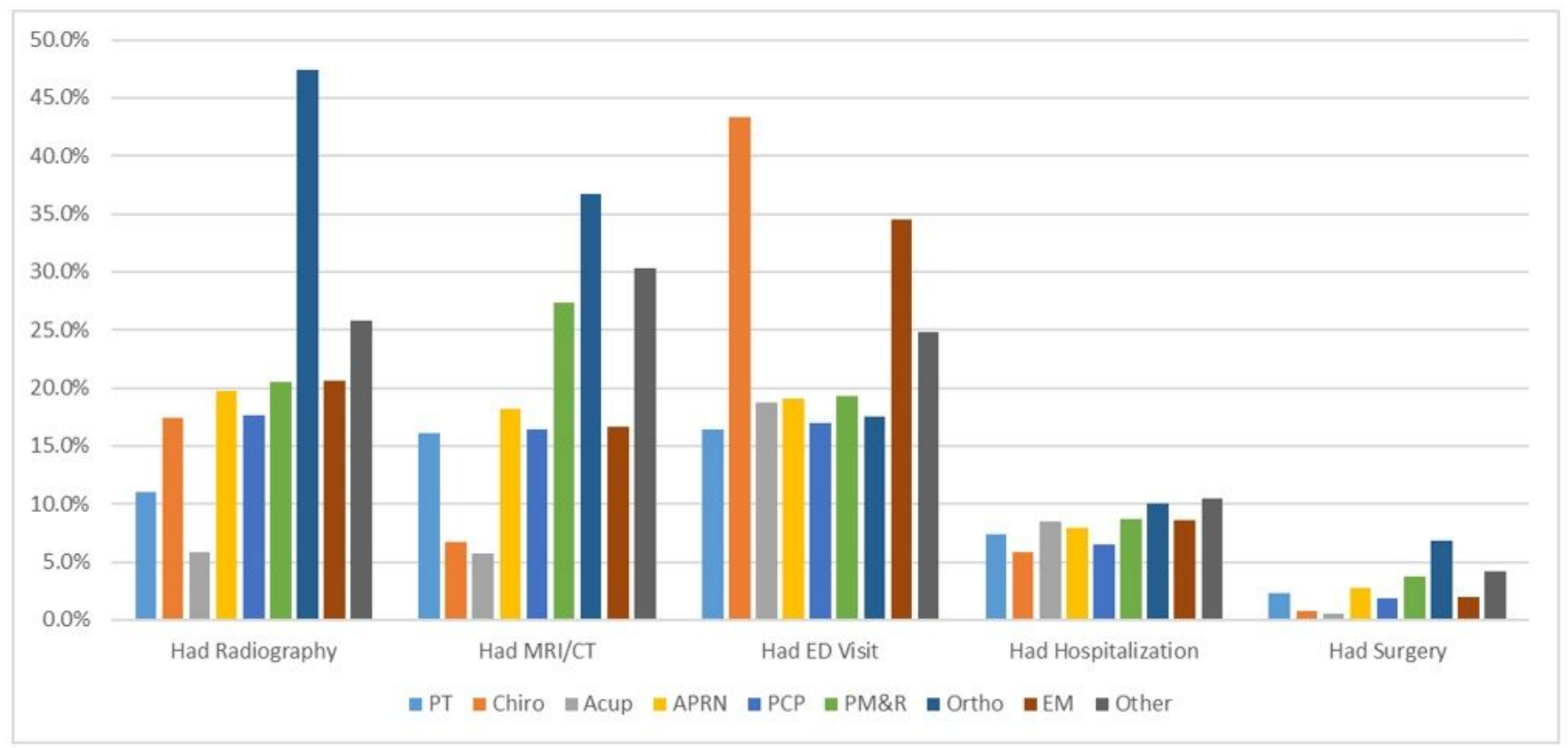

\section{Figure 1}

Health Care Utilization Adjusted Rates by First Provider Seen for Low Back Pain. PT= physical therapist; Chiro = chiropractor; Acu = acupuncturist; APRN = advanced practice registered nurse; $\mathrm{PCP}=$ primary care physician; $\mathrm{PM} \& \mathrm{R}=$ physical medicine and rehabilitation physician; Ortho = orthopedist; $\mathrm{EM}=$ emergency medicine physician 


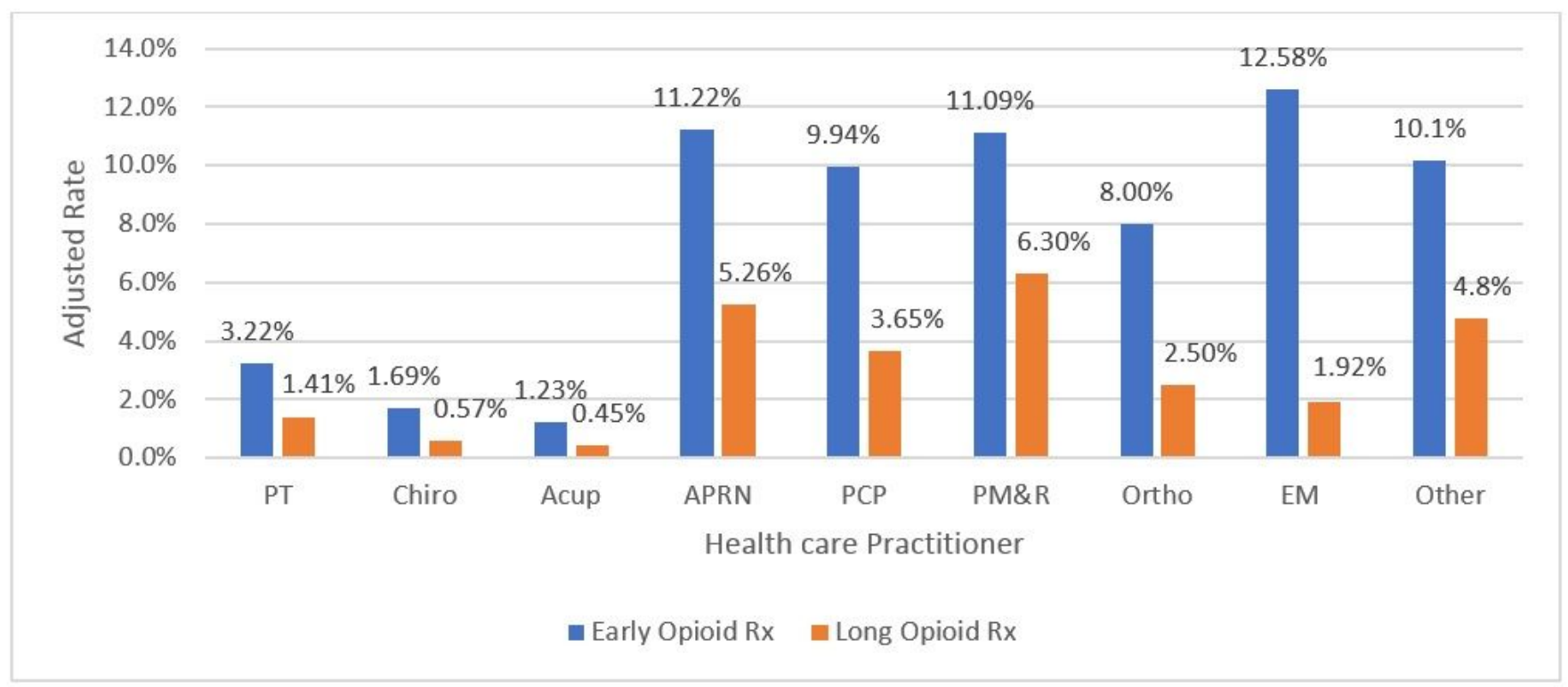

\section{Figure 2}

Early and Long Opioid Prescription (Adjusted Rates) by First Provider Seen for Low Back Pain. PT= physical therapist; Chiro = chiropractor; Acu = acupuncturist; $A P R N=$ advanced practice registered nurse; $P C P=$ primary care physician; $P M \& R=$ physical medicine and rehabilitation physician; Ortho = orthopedist; $\mathrm{EM}=$ emergency medicine physician

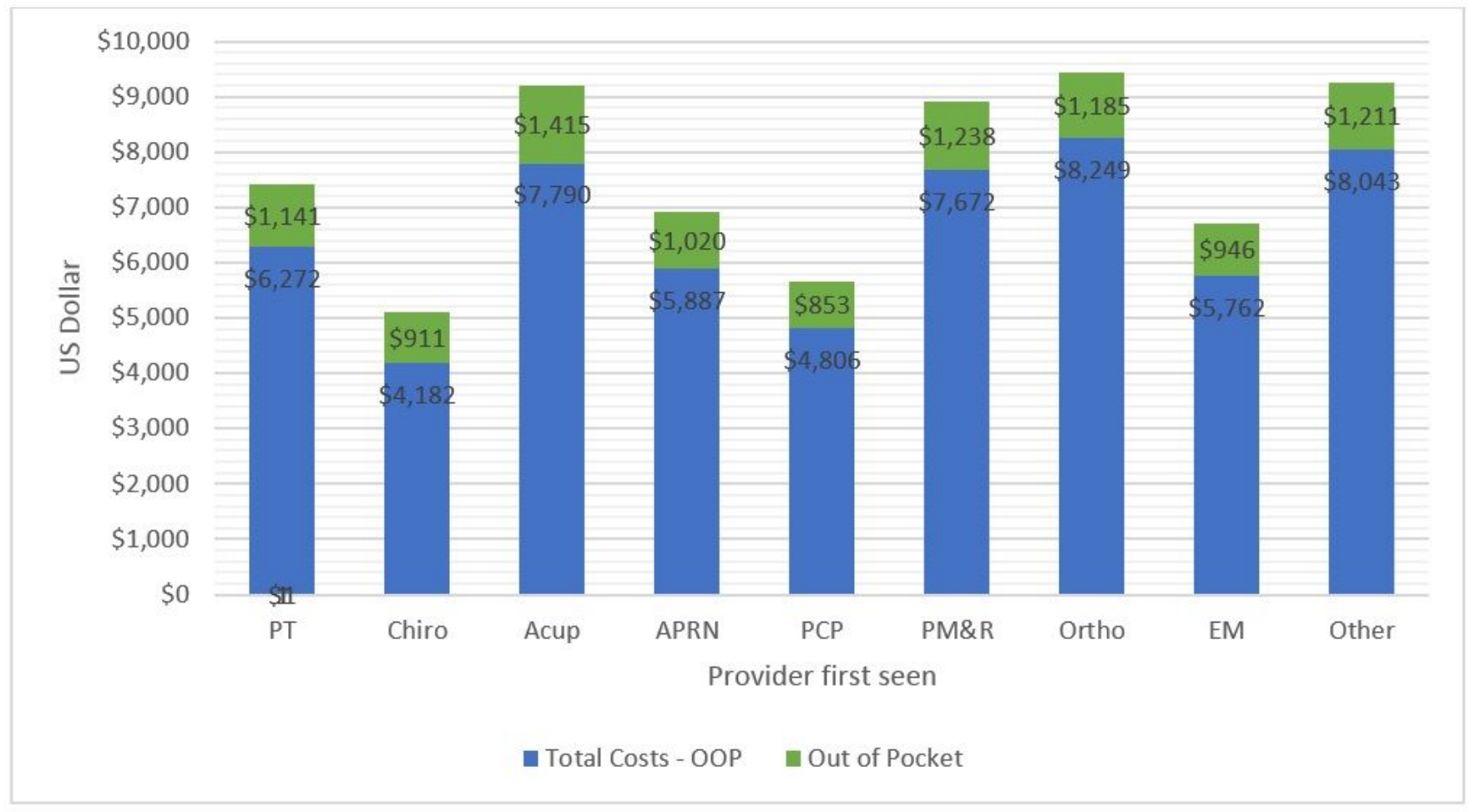

\section{Figure 3}

Adjusted Health Care Costs (Total and Out of Pocket (OOP) Costs by First Provider Seen for Low Back Pain. PT= physical therapist; Chiro = chiropractor; Acu = acupuncturist; $A P R N=$ advanced practice registered nurse; $\mathrm{PCP}=$ primary care physician; $\mathrm{PM} \& \mathrm{R}=$ physical medicine and rehabilitation physician; Ortho = orthopedist; $\mathrm{EM}=$ emergency medicine physician

\section{Supplementary Files}

This is a list of supplementary files associated with this preprint. Click to download.

- WheretoStartAppendicesv2.docx 